\title{
Use of Transgenic and Mutant Animal Models in the Study of Heterocyclic Amine-induced Mutagenesis and Carcinogenesis
}

\author{
Roderick H. Dashwood* \\ Department of Environmental \& Molecular Toxicology, and Linus Pauling Institute, Oregon State University, \\ Corvallis, OR 97331-6512, USA
}

Received 18 November 2002

\begin{abstract}
Heterocyclic amines (HCAs) are potent mutagens generated during the cooking of meat and fish, and several of these compounds produce tumors in conventional experimental animals. During the past 5 years or So, HCAs have been tested in a number of novel in vivo murine models, including the following: lacZ, lacI, cII, c-myc/lacZ, $r p s L$, and gpt $\Delta$ transgenics, $\mathrm{XPA}^{-/}, \mathrm{XPC}^{-/}, \mathrm{Msh}^{+/-}, \mathrm{Msh}^{-/-}$ and $p 53^{+/ /}$knock-outs, $A p c$ mutant mice (Apc ${ }^{\Delta 716}, A p c^{1638 \mathrm{~N}}$, $A p c^{\text {min }}$ ), and $A 33^{\Delta N \beta \text {-cat }}$ knock-in mice. Several of these models have provided insights into the mutation spectra induced in vivo by HCAs in target and non-target organs for tumorigenesis, as well as demonstrating enhanced susceptibility to HCA-induced tumors and preneoplastic lesions. This review describes several of the more recent reports in which novel animal models were used to examine HCA-induced mutagenesis and carcinogenesis in vivo, including a number of studies which assessed the inhibitory activities of chemopreventive agents such as 1,2dithiole-3-thione, conjugated linoleic acids, tea, curcumin, chlorophyllin-chitosan, and sulindac.
\end{abstract}

Keywords: Big Blue ${ }^{\circledast}$ mouse, $\beta$-Catenin, Chemoprevention, Chlorophyllin, Conjugated linoleic acids, Curcumin, 1,2Dithiole-3-thione, Heterocyclic amines, MutaMouse, Sulindac, Tea

\section{Introduction}

The carcinogenic activity of cooked horsemeat extract was first described more than 60 years ago (Widmark, 1939). However, it was the discovery by Sugimura $e t$ al. of potent mutagens in extracts of cooked meat and fish (Sugimura et al.,

*To whom correspondence should be addressed. Tel: 1-541-737-5086; Fax: 1-541-737-5077

E-mail: Rod.Dashwood@oregonstate.edu
1977) that generated major interest in heterocyclic amines (HCAs) as potential etiological agents in the development of human cancer. A wide range of topics related to HCAs has been published in the scientific literature, as evidenced by a text on "Food Borne Carcinogens: Heterocyclic Amines" (edited by Nagao and Sugimura, 2000) with chapters on organic synthesis, content in foods and beverages, metabolism, interactions with cellular macromolecules, mutagenicity, carcinogenicity in animals and in specific target organs, degenerative changes, antimutagenesis/ anticarcinogenesis, and epidemiology. Recent reviews have provided updates on these various topics, including discussion of several specific HCAs mentioned below (Hein et al., 2000; Schoeffner and Thorgeirsson, 2000; Schwab et al., 2000; Dashwood, 2002; Felton et al., 2002; Nagao et al., 2002; Skog, 2002; Skog and Solyakov, 2002; Turesky, 2002).

Research conducted during the past two decades on HCAs has laid the foundation for several new avenues of investigation. One rapidly developing area is in the use of novel test species, including transgenic, knock-out, and knock-in animal models. This review presents some of the more recent applications of these in vivo models in the study of HCA-induced mutagenesis and carcinogenesis.

\section{Studies with HCAs in lacZ Transgenic Mice}

2-Amino-1-methyl-6-phenylimidazo[4,5-b]pyridine (PhIP) is the most abundant HCA mutagen in fried ground beef and induces colon, prostate, and mammary cancer in the rat (reviewed in Nagao and Sugimura, 2000). Genetic analysis of lacZ mutations induced by PhIP in the intestine of MutaMouse has been reported (Lynch et al., 1998). Mice were given PhIP orally at a dose of $20 \mathrm{mg} / \mathrm{kg}$ for 4 days and killed 7 days later. Genomic DNA was extracted from several tissues, including the small intestine and large intestine, and the mutation frequency at the lac $Z$ locus was determined. Mutant lacZclones from the intestine also were characterized 
using PCR and DNA sequencing. In total, 57 lacZ mutants from PhIP-treated and untreated mice were analyzed. In mutants from the PhIP-treated group, 33\% were $\mathrm{G}: \mathrm{C} \rightarrow \mathrm{T}: \mathrm{A}$ transversions, from a total of $65 \%$ base substitutions, compared with $17 \%$ in the vehicle controls. In untreated control mice, $39 \%$ of mutants were $\mathrm{G}: \mathrm{C} \rightarrow \mathrm{A}: \mathrm{T}$ transitions from a total of $72 \%$ base substitutions. This study confirmed that PhIP was mutagenic to the intestine of the MutaMouse, and that the carcinogen produced a spectrum of mutations that was distinct from the genetic changes that arose spontaneously in untreated controls.

In other studies (Davis et al., 1996; Ryu et al., 1999), mice carrying the lac $Z$ target gene were crossed with C57B1 control mice or c-myc transgenic mice to produce C57B1/lacZ and c-myc/lacZ mice strains, respectively, and these animals were given one of three different HCAs. Specifically, mice were treated p.o. with 10 daily doses of $20 \mathrm{mg} / \mathrm{kg}$ 2-amino-3methylimidazo[4,5-f]quinoline (IQ), 2-amino-3,8-dimethylimidazo [4,5-f]quinoxaline (MeIQx), or 2-amino-9H-pyrido[2,3-b] indole $(\mathrm{AaC})$. The frequency of hepatic lac $Z$ gene mutations in C57B1/lacZ and c-myc/lacZ mice was significantly higher in mice treated with HCAs compared with mice given vehicle alone, and all three HCAs formed hepatic DNA adducts. In both strains of mice hepatic DNA adduct levels were 2-3-fold higher with $\mathrm{AaC}$ than with either IQ or MeIQx, although mutation frequencies in the $l a c Z$ gene were $30-40 \%$ lower in mice dosed with $\mathrm{AaC}$. The latter finding suggested that AaCDNA adducts may be less mutagenic in vivo than either MeIQx- or IQ-DNA adducts. The lacZ mutation frequencies observed for all three HCAs appeared to be influenced by cmyc transgene expression, being $30-40 \%$ higher in HCAinduced mice carrying the c-myc gene compared with mice not carrying this transgene. No significant differences were detected in lacZ mutation frequencies among C57B1/lacZ and c-myc/lacZ mice given vehicle alone. Additional work revealed that IQ- and MeIQx-DNA adducts were 2-3-fold higher in c-myc/lacZ mice than in C57B1/lacZ mice, whereas AaC-DNA adducts were not statistically different between the two strains. The authors concluded that over expression of the c-myc oncogene cooperates with the HCAs in vivo to enhance mutagenicity (Davis et al., 1996). In follow-up studies, MeIQx-induced hepatic tumor incidences at 40 weeks were found to be $100 \% / 75 \%(17 \% / 0 \%)$ and $44 \% / 17 \%(0 \% / 0 \%)$ in male c-myc/lambda lacZ and C57B1/lambda lacZ mice given carcinogen (or control) diet, respectively, supporting a synergism between MeIQx and c-myc overexpression in hepatocarcinogenesis (Ryu et al., 1999).

\section{Studies with HCAs in Murine Models Containing lacI and $c I I$ Transgenes}

Mice or rats carrying lacI and cII transgenes provided information on the target organ specificity and mutation spectrum characteristics of MeIQx, PhIP, and IQ in vivo (Bol et al., 2000; Itoh et al., 2000; Stuart et al., 2000, 2001). Thus, in studies using the transgenic Big Blue ${ }^{\circledR}$ mouse, lacI mutant frequencies were examined in the liver and colon after a single intragastric (i.g.) dose of MeIQx, or after 12 weeks of feeding MeIQx in the diet (Itoh et al., 2000). Micronucleus induction was monitored in the peripheral blood, and cell proliferation was monitored in various tissues using proliferating cell nuclear antigen (PCNA) immunostaining. A single i.g. dose of MeIQx $(100 \mathrm{mg} / \mathrm{kg})$ did not increase mutation frequencies in liver or colon, but it did induce a slight increase in the incidence of micronucleated reticulocytes $48 \mathrm{~h}$ after HCA treatment. No apparent increase in PCNA-positive foci was detected in any of the tissues analyzed 14 days after MeIQx exposure. However, administration of 300 parts per million (ppm) MeIQx in the diet for 12 weeks caused mutation frequencies to increase in liver and colon, with greater increases detected in female mice. The sex difference in mutation frequencies was consistent with the finding that female mice were more susceptible to MeIQx-induced carcinogenesis. These results demonstrated that in the transgenic mouse mutation assay, chronic administration of MeIQx was effective in inducing mutagenicity in the known target organs for carcinogenicity.

Stuart et al. examined the mutations induced by $\mathrm{PhIP}$ in rats containing lacI and cII transgenes (Stuart et al., 2000, 2001). In one study, the frequency and specificity of PhIP-induced mutations was determined in the cecum, proximal colon, and distal colon of male and female lacI transgenic rats (Stuart et $a l .$, 2001). After 61 days of treatment with 200 ppm PhIP in the diet, carcinogen-induced mutation frequencies were elevated 7-fold in the cecum and 14- to 21-fold in the colon of male and female rats compared with untreated controls. In these tissues, the mutation spectrum was determined for a total of 754 PhIP-induced mutants ( 363 from males, 391 from females). The mutational spectra consisted predominantly of $\mathrm{G}: \mathrm{C} \rightarrow \mathrm{T}: \mathrm{A}$ and $\mathrm{G}: \mathrm{C} \rightarrow \mathrm{C}: \mathrm{G}$ transversions and deletions of $\mathrm{G}: \mathrm{C}$ base pairs. Interestingly, no significant differences were seen in the mutational spectra with respect to sex or position in the colon. Therefore, the authors concluded that following induction of mutations by PhIP in male and female colons, non-mutagenic factors, possibly hormonal, preferentially influence the formation of tumors in the colon of male rats.

In another study with $\mathrm{PhIP}$, the mutation spectrum of the $c I I$ gene from the colon of the Big Blue ${ }^{\circledR}$ F344 rat was compared with the mutation spectrum determined previously in the lacI transgene from colon of the same group of animals. Analysis of the mutation frequencies in the two transgenes, including nearest neighbor analyses of mutated nucleotides and the number of mutational target sequences in each gene, indicated that PhIP-induced mutational specificity was similar in both genes (Stuart et al., 2000).

Bol et al. conducted a mutational analysis of the liver, colon, and kidney of Big Blue ${ }^{\circledR}$ rats treated with IQ (Bol et al., 2000). At the highest dose of IQ tested $(20 \mathrm{mg} / \mathrm{kg}$ p.o. for 5 consecutive days), mutation frequencies were increased 
significantly above background frequencies, and they were highest in the liver, followed by the colon and the kidney. The hepatic IQ-induced mutation spectrum was significantly different to that observed in control rats. Examination of the lacI mutation spectra in the liver, colon and kidney from IQtreated rats showed an increase in GC transversions (liver and colon) and $1 \mathrm{bp}$ G:C deletions (liver and kidney). Interestingly, a single $\mathrm{G}$ deletion in the sequence 5'-CGGGA3', characteristic of PhIP exposure, was detected in the liver and colon of rats given IQ. In addition, a 2 bp GC deletion was identified at an identical position in the liver, colon and kidney, and the colon had two larger deletions of 13 and 33 bp. A preference was observed for base substitution mutations at guanine in the sequence 5'-CGC/T-3' and for 1 bp deletions at the guanine doublet in the sequence 5'-CGGA-3', especially in the liver and colon. The authors concluded that using the lacI gene as marker in the rat, IQ-induced mutations have similarities to those identified for other HCAs studied in the same experimental system, but not to mutations identified in IQ-induced tumors (Bol et al. 2000).

Okochi et al. (1999) also reported on the induction of lacI mutations in the mammary gland of PhIP-treated female Big Blue $^{\circledR}$ rats. Mutant frequencies were increased 13-fold in PhIP-treated rats compared with controls. In the latter group, $\mathrm{G}: \mathrm{C} \rightarrow \mathrm{A}: \mathrm{T}$ transitions at $\mathrm{CpG}$ sites were most frequent, whereas in the PhIP-treated group $\mathrm{G}: \mathrm{C} \rightarrow \mathrm{T}: \mathrm{A}$ transversions predominated $(43 \%)$, followed by single base pair deletions of G:C $(21 \%)$. A total of nine deletions was detected involving 5'-GGGA-3' sites. Comparison of PhIP-induced mutations in the mammary gland with those previously reported in the colon revealed that $\mathrm{G}: \mathrm{C} \rightarrow \mathrm{T}: \mathrm{A}$ transversions occurred at a significantly higher frequency in the mammary gland and that G:C deletions occurred at a significantly lower frequency. However, the signature mutation, $G$ deletion at the 5'-GGGA3 ' site, was commonly observed in both tissues (Okochi et al., 1999).

In addition to studies with the HCAs alone, some reports have described the modulatory activities of dietary compounds on HCA-induced mutagenesis in transgenic species, including experiments with lacI transgenic rodents. In one study, the in vivo antimutagenic efficacy of two dietary chemopreventive agents, 1,2-dithiole-3-thione (DTT) and conjugated linoleic acids (CLA), was explored in lacI transgenic rats given $\mathrm{PhIP}$ (Yang et al., 2001). Male Big Blue ${ }^{\circledR}$ rats were fed a diet containing $0.005 \%$ DTT or $0.5 \%$ CLA starting one week prior to giving $200 \mathrm{ppm} \mathrm{PhIP}$ in the diet for 61 days. The colonic mutation frequencies were increased by $\mathrm{PhIP}$ 8-16-fold versus controls, and CLA and DTT reduced the PhIP-induced mutation frequencies in the distal colon by $14 \%$ and $24 \%$, respectively. The frequency of -1 frameshift mutations was lower in the distal colon of CLA- and DTTtreated rats. However, the PhIP-induced mutation frequencies in the cecum ( -1 frameshifts and $\mathrm{GC} \rightarrow \mathrm{TA}$ transversions) were elevated by $43 \%$ after treatment with CLA. It was concluded that CLA and DTT modulate PhIP-induced mutagenesis in a tissue-specific manner (Yang et al., 2001). In a follow-up study with CLA and PhIP in vivo, lacI mutations were examined in the kidney (Yang et al., 2002). Exposure to $100 \mathrm{ppm}$ PhIP in the diet for 47 days elevated lacI mutation frequencies in the kidney, and mutation frequencies were increased to a greater extent in males than females, being $300 \%$ and $60 \%$ higher, respectively, than the corresponding controls. Notably, CLA completely inhibited the formation of PhIP-induced mutations in the kidney of female rats. Examination of the mutation spectra in males revealed no significant differences for groups given $\mathrm{PhIP}$ versus PhIP plus CLA. Mutations were identified as -1 frameshifts, involving loss of G:C and A:T bp. It was concluded that the kidney of these rats responded in a sexdependent manner to mutagenesis and antimutagenesis by PhIP and CLA.

\section{Studies with HCAs in rpsL Transgenic Mice}

In addition to chemoprevention studies with CLA and DTT, one report described the inhibitory properties of chlorophyllin-chitosan against 3-amino-1-methyl-5H-pyrido [4,3-b]indole (Trp-P-2)-induced mutagenesis in mice carrying the E. coli rpsL transgene (Anzai et al., 2001). Mice given a diet containing $0.002 \%$ or $0.01 \%$ Trp-P-2 had dose-dependent increases in carcinogen-DNA adducts in various tissues, with the highest levels being detected in the liver. Addition of $3 \%$ chlorophyllin-chitosan to the diet reduced Trp-P-2 adduct levels by up to $90 \%$. Mutation frequencies in the rpsL gene were increased significantly in both the liver and spleen following administration of $0.01 \%$ Trp-P-2 in the diet, and mutation frequencies were reduced to background levels following administration of chlorophyllin-chitosan, with no evidence of toxicity or other deleterious effects. The results showed that chlorophyllin-chitosan protected against the genotoxic action of Trp-P-2 in vivo, and suggested that additional studies are warranted with chlorophyllin-chitosan against other HCAs.

\section{Studies with HCAs in gpt $\Delta$ Transgenic Mice}

Masumura et al. $(1999,2000)$ used PhIP in a new mouse strain that facilitates the detection of two different types of mutation, namely 6-thioguanine selection for point mutations and Spi selection for deletions. Mice were given $400 \mathrm{ppm}$ PhIP in the diet for 13 weeks and gpt and Spi mutations were analyzed from the colon, where the highest mutant frequencies were detected. In the case of gpt mutations induced by PhIP, $81 \%$ were single base pair substitutions, $\mathrm{G}: \mathrm{C} \rightarrow \mathrm{T}: \mathrm{A}$ transversions being most frequent, although single base pair deletions at $\mathrm{G}: \mathrm{C}$ base pairs also were observed. In untreated mice, $\mathrm{G}: \mathrm{C} \rightarrow \mathrm{A}: \mathrm{T}$ transitions predominated, most occurring at CpG sites. Three quarters of the Spi mutants detected in PhIP- 
treated mice were G:C base pair deletions, more than half of which involved runs of $\mathrm{G}$ or $\mathrm{C}$ sequences. In addition, a novel frameshift motif was observed involving $\mathrm{G}: \mathrm{C}$ base pair deletions beside run sequences, the most frequent of which was a TTTTTTG $\rightarrow$ TTTTTT. The authors concluded that $\mathrm{PhIP}$ induced point mutations (single base pair deletions, base substitutions) rather than larger deletions in vivo and that run sequences may be important, as suggested in prior studies using PhIP in more conventional animal models, such as the F344 rat (Kakiuchi et al. 1995).

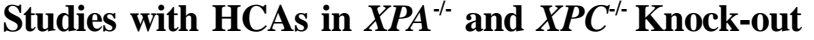 Mice}

Klein et al. (2001) investigated the intestinal toxicity and carcinogenic potential of PhIP in DNA repair deficient $X P A^{-/}$ mice. $X P A^{--}$knockout mice lacking a functional nucleotide excision repair pathway were exposed to dietary concentrations of PhIP in the range 10-200 ppm. The HCA was highly toxic to $X P A{ }^{-}{ }^{-}$mice, even at doses 10 -fold lower than those tolerated by wild-type C57BL/6 mice, and at the higher doses of 100 and $200 \mathrm{ppm}$ PhIP, $X P A^{-1}$ mice died after only 2 and 6 weeks, respectively, with evidence of gross abnormalities in the small intestine. Mutation analyses in $X P A^{-1}$ mice carrying a lac $Z$ reporter gene revealed genotoxic effects of PhIP in the small intestine; thus, lac $Z$ mutant frequencies were selectively and dose-dependently increased in the intestinal DNA after carcinogen treatment. In marked contrast, $X P C^{-1-}$ mice, which retain the ability to repair DNA damage in actively transcribed genes, showed no toxicity in response to treatment with $100 \mathrm{ppm}$ PhIP. This suggested that transcription coupled repair of PhIP-DNA adducts in active genes plays a crucial role in preventing the intestinal toxicity of PhIP. Interestingly, subtoxic doses of PhIP administered to $X P A^{-1-}$ mice for 6 months increased the tumor incidences when the study was terminated at 1 year, with lymphomas observed following treatment with $10 \mathrm{ppm} \mathrm{PhIP}$ and lymphomas plus intestinal tumors seen at the higher dose of $25 \mathrm{ppm}$ PhIP.

\section{Studies with HCAs in $M s h 2^{+/-}$and $M s h 2^{-/-}$Knock- out Mice}

Zhang et al. (2001) investigated whether the loss of one or both alleles of the $M s h 2$ gene might increase the mutational sensitivity of mice exposed to PhIP. Msh2 $2^{+-} / l a c I$ and $M s h 2^{-1-}$ lacI double transgenic mice were treated with $\mathrm{PhIP}$ and lacI mutations were studied in the colon. The spontaneous mutation frequency was 8-fold higher in $\mathrm{Msh}^{-/-}$mice than in $M s h^{+-}$and wild-type $M s h 2^{+/+}$mice, and PhIP induced a significant increase in mutation frequencies in all three genotypes, most notably in the $M s h 2^{--}$mice. The latter mice displayed an increased frequency of PhIP-induced G:C $\rightarrow$ A:T transitions, whereas $M s h 2^{+-}$mice had increased levels of
$\mathrm{G}: \mathrm{C} \rightarrow \mathrm{T}: \mathrm{A}$ transversions and -1 frameshifts following PhIP treatment. The authors suggested that a defect in mismatch repair results in enhanced sensitivity to PhIP exposure, highlighting the possible importance of combined genetic and environmental factors in HCA-induced carcinogenesis.

\section{Studies with HCAs in $p 53^{+/-}$Knock-out Mice}

$p 53^{+-}$mice were used in studies with IQ, MeIQx, and PhIP (Dass et al., 1999; Morimura et al., 1999; Park et al. 1999), but in all cases the major conclusion was that $p 53^{+-}$mice offer no practical advantage as a test species for short-term carcinogenicity tests involving HCAs. In studies with IQ, which is an established liver and colon carcinogen in the F344 rat, doses of $0,0.4,2,10$ and $50 \mathrm{ppm}$ in the diet produced no preneoplastic hepatic foci in either $p 53^{+-}$or wild-type mice. Interestingly, colonic aberrant crypts were detected in the three highest IQ dose-groups, but subsequent studies were not undertaken to determine whether $p 53^{+/-}$mice are at increased susceptibility for frank colon tumors in response to IQ treatment (Morimura et al., 1999).

MeIQx is a potent mutagen in vitro and induces liver, skin and Zymbals gland tumors in the F344 rat and liver, lung and hematopoietic tumors in CDF1 mice. Male and female $p 53^{+-}$ mice and wild type littermates were administered diets containing $0,0.1,1,10$ and 100 ppm MeIQx for 1 year. No significant differences were observed among the various groups, other than an increase in liver adenomas in males receiving 10 ppm MeIQx (Park et al., 1999).

$\mathrm{PhIP}$ also was tested in $\mathrm{p} 53^{+/-}$and wild-type mice. The results showed that $\mathrm{PhIP}$ was not tumorigenic in either group of mice, although liver tumor incidence was increased significantly in wild-type (but not $\mathrm{p} 53^{+/}$) mice treated with dimethylnitrosamine or 6-nitrochrysene (Dass et al., 1999). The authors concluded that a deficiency in the amount of p53 protein does not lead to accelerated PhIP-induced liver tumorigenesis.

\section{Studies with HCAs in Apc Mutant Mouse Models}

Damage to the human adenomatous polyposis coli (APC) gene is responsible for many cases of sporadic colon cancer and underlies the inherited predisposition known as familial adenomatous polyposis (FAP). Oshima et al. (1996) constructed $A p c^{\Delta 716}$ knockout mice with a truncation mutation in the $A p c$ gene and found that these mice developed intestinal polyps spontaneously. When $\mathrm{PhIP}$ was fed to $A p c^{\Delta 716}$ mice at $400 \mathrm{ppm}$ for $8 \mathrm{wk}$, the total polyp number did not increase significantly but the polyp distribution shifted to a larger size range. Similar, but weaker, effects were observed with IQ and MeIQx in $A p c^{\Delta 716}$ mice. Interestingly, i.p injections of $50 \mathrm{mg} /$ $\mathrm{kg}$ 2-hydroxyamino-1-methyl-6-phenylimidazo[4,5-b]pyridine $(\mathrm{N}$-OH-PhIP), a direct acting metabolite of $\mathrm{PhIP}$, for five 
consecutive days increased the polyp number significantly. This increase was not associated with augmented mutation of the $A p c$ gene, but rather the loss of a full-length $A p c$ allele in many of the polyps.

Sorensen et al. (1997) employed an alternative model, designated $A p c^{1638 \mathrm{~N}}$ mice, which are heterozygous for a targeted frameshift mutation at codon 1638 of the Apc gene, and which are predisposed to multiple adenomas and adenocarcinomas along the GI tract. Upon dietary administration of $0.03 \% \mathrm{PhIP}$ in a 6 month study, a significant increase was observed in the number of small intestinal tumors and aberrant crypt foci in male $A p c^{1638 \mathrm{~N}}$ mice, compared with untreated transgenic mice. No differences were observed between PhIP-treated and control female mice.

Probably the most widely used mouse model in which the $A p c$ gene is altered is the $A p c^{\mathrm{min}}$ mouse. The latter mouse model is genetically predisposed to intestinal polyp formation due to impaired function of the Apc protein, resulting from a mutation that introduces a premature translational stop codon at amino acid 850. Exposure of $A p c^{\text {min }}$ mice to PhIP or IQ greatly increases the tumorigenesis observed in the GI tract (Andreassen et al., 2002, 2001; Paulsen et al., 1999). In one study, neonatal $A p c^{\min }$ mice (3-6 days old) were exposed to PhIP via breast milk from lactating dams given 8 s.c. injections of $50 \mathrm{mg} / \mathrm{kg}$ PhIP three times a week, or to 8 s.c. injections of 25 or $50 \mathrm{mg} / \mathrm{kg}$ PhIP directly, over the same period. At the age of 11 weeks, 2-4-fold and 6-9-fold increases were observed in the number of small intestinal tumors in $A p c^{\mathrm{min}}$ mice exposed, respectively, to PhIP via breast milk or via direct injection. In the colon, the corresponding increases were 3-4-fold and 2-6-fold, respectively. These findings revealed an enhanced tumorigenic effect of $\mathrm{PhIP}$ in neonatally exposed $A p c^{\mathrm{min}}$ mice, even after exposure via breast milk from PhIP-exposed dams (Paulsen et al., 1999).

In a follow-up study in $A p c^{\mathrm{min}}$ mice, genetic analyses were undertaken to determine whether the $A p c$ gene was affected in small intestinal and colonic tumors induced by $\mathrm{PhIP}$. In the spontaneous polyps the main mechanism for tumor induction was loss of heterozygosity ( $\mathrm{LOH}$ ) resulting in loss of the wildtype $\mathrm{Apc}^{+}$allele. PhIP-induced tumors also exhibited LOH, but mechanisms other than $\mathrm{LOH}$ were implicated. Tumors that had retained the wild-type $A p c^{+}$allele were examined for the presence of truncated Apc proteins. Truncated Apc proteins involving exon 15 of the $A p c$ gene were detected in $20 \%$ ( 8 of 40 ) of the intestinal tumors and $17 \%$ of the colon tumors (2/12) not showing $\mathrm{LOH}$ after $\mathrm{PhIP}$ exposure. Importantly, no truncated proteins were detected in tumors from unexposed mice carrying a wild-type $A p c^{+}$allele. The results showed that PhIP-induced intestinal tumors in $A p c^{\min }$ mice are characterized by $\mathrm{LOH}$ and truncation mutations in the wild-type $A p c^{+}$allele (Andreassen et al. 2001).

A comparative study in neonatal $A p c^{\text {min }}$ mice given a single dose of IQ or PhIP (one injection of $50 \mathrm{mg} / \mathrm{kg}$ ) showed a twoand three-fold increase, respectively, in the number of small intestinal tumors (Andreassen et al., 2002). The number of colonic tumors also was increased in males, but not in females. As in prior studies (Andreassen et al. 2001), the main mechanism for tumor induction in spontaneously formed and in IQ-induced small intestinal and colonic tumors was LOH (84-88\% frequency). In contrast, only $55 \%$ of the PhIPinduced small intestinal tumors from males showed LOH, whereas several of the tumors lacking $\mathrm{LOH}$ had truncated Apc proteins, indicative of truncation mutations in exon 15 of the $A p c$ gene. PhIP-induced mutations were detected at codon 1125 (C deletion) and 1130 (G-T transversion), and the IQinduced mutation was at codon 956 (C-T transition). The authors concluded that one injection of either PhIP or IQ was sufficient to increase significantly the intestinal tumors detected in $A p c^{\min }$ mice, and that this involved inactivation of the wild-type Apc allele either by causing LOH or truncation mutations (Andreassen et al., 2002).

Steffensen et al. (2002) reported recently that the HCA food mutagen $\mathrm{AaC}$, but not its structurally-related methylated form, MeAaC, increased intestinal tumorigenesis in neonatally exposed $A p c^{\min }$ mice. Litters of $A p c^{\min }$ and wildtype mice of both sexes were given a s.c. injection of 0.22 $\mathrm{mmol} / \mathrm{kg} \mathrm{AaC}$ or MeAaC (or vehicle alone) on days 3-6 after birth, and they were killed after 11 weeks. AaC increased the number and diameter of small intestinal tumors, but not the number of colonic tumors or dysplastic aberrant crypt foci, in female and male $A p c^{\mathrm{min}}$ mice. Interestingly, the pooled data for females and males suggested that colon tumors and aberrant crypt foci detected following $\mathrm{AaC}$ exposure were smaller than the spontaneous lesions, suggesting later induction and/or slower progression of aberrant crypts in mice given $\mathrm{AaC}$. In marked contrast to the findings with $\mathrm{AaC}, \mathrm{MeAaC}$ did not affect intestinal tumorigenesis in $A p c^{\text {min }}$ mice (Steffensen et al., 2002).

In addition to the studies discussed above which used HCAs together with chemopreventive agents such as CLA, DTT or chlorophyllin-chitosan, one recent report described the protection by curcumin against PhIP-induced tumorigenesis in $A p c^{\mathrm{min}}$ mice (Collett et al., 2001). Curcumin, a chemopreventive agent which promotes apoptosis in the GI tract, is the active ingredient of the rhizome of Curcuma longa used commonly in Indian cuisine. In wild-type compared with $A p c^{\min }$ mice, the intestinal epithelial apoptotic index was 2fold higher following PhIP treatment, and tumor formation was augmented significantly [4.6 tumors per PhIP-treated mouse versus 2.1 tumors per control (untreated) mouse]. Curcumin enhanced PhIP-induced apoptosis and inhibited PhIP-induced tumorigenesis in the proximal small intestine. The investigation revealed that the $A p c^{\min }$ genotype was associated with resistance to PhIP-induced apoptosis in the intestinal epithelium, and that curcumin overcame this resistance to apoptosis and inhibited PhIP-induced tumorigenesis in the proximal small intestine. 


\section{Studies with HCAs in $A 33^{\Delta N \beta-c a t}$ Knock-in Mutant Mice}

The previous section presented several studies using $A p c$ mutant mice, in which $\beta$-catenin/Tcf gene activation occurs due to the inability to downregulate $\beta$-catenin (for Wnt signaling reviews, see Polakis 2000; Huelsken and Behrens, 2002). A new mouse model, in which $\beta$-catenin is conditionally over-expressed in the GI tract, was used to study HCA-induced carcinogenesis and its modulation by dietary factors (Orner et al., 2002a, 2002c). A33 ${ }^{\Delta \mathrm{NB}-\mathrm{cat}}$ mice express in the intestinal epithelium an oncogenic, $N$-truncated form of $\beta$ catenin as a knock-in transgene. Thus, following activation via the Cre/lox system, a truncated $\beta$-catenin protein is expressed which lacks 131 amino acids, including the entire glycogen synthase kinase- $3 \beta$ regulatory domain. These mice exhibited a much less severe phenotype than $A p c^{\text {min }}$ mice, but $A 33^{\Delta \mathrm{N} \beta \text {-cat }}$ mice were significantly more sensitive to carcinogens such as $\mathrm{PhIP}$ and azoxymethane (Tebbutt et al., 2000; Orner et al., 2002a, 2002c). Interestingly, $A 33^{\Delta \mathrm{N} \beta-\mathrm{cat}}$ mice developed colonic aberrant crypt foci spontaneously, but PhIP treatment increased the incidence and number of these lesions per colon (Orner et al., 2002a). Carcinogen-induced $A 33^{\Delta \mathrm{NA} \text {-cat }}$ mice also developed polyps after 1 year that were localized exclusively to the colon, with none being detected in the small intestine (Orner et al., 2002c and unpublished results). This distribution contrasts with other animal models in which small intestinal tumors predominate, such as the $A p c^{\min }$ mouse. The colonspecific localization of polyps makes the $A 33^{\Delta \mathrm{N} \beta \text {-cat }}$ mouse highly attractive for studies with chemopreventive and therapeutic agents. For example, in one study, the combination of tea plus a non-steroidal anti-inflammatory agent (sulindac) inhibited polyp formation significantly in the $A 33^{\Delta \text { NS-cat }}$ mouse, and there was a marked decrease in $\beta$-catenin protein expression in the colonic mucosa after treatment with the test agents (Orner et al., 2002c). The data suggested a chemopreventive role for combined tea plus sulindac treatment, acting to downregulate $\beta$-catenin/Tcf signaling. These findings recapitulated the results obtained from studies with tea and sulindac in $A p c^{\min }$ mice (Orner et al., 2002a, 2002b, 2002c).

\section{Conclusions}

The present paper has reviewed a number of reports in which transgenic, knock-out, and knock-in animal models were used in the investigation of HCA-induced mutagenesis and carcinogenesis, including studies with chemopreventive agents. The various animal models provided new insights into the mutation spectra generated by HCAs in various target and non-target organs, as well as demonstrating increased susceptibility to preneoplastic lesions and frank tumors in response to HCA treatment. It is likely that this avenue of investigation will continue to grow rapidly in the future, and that newly developed animal models will be used to examine the interaction of genetic and dietary factors and their role in determining susceptibility to HCAs and other environmental risk factors. An important consideration in the application of such models will be the extent to which they provide useful additional mechanistic insight, above and beyond that obtained from more convention in vivo models.

Acknowledgments Results from the authors laboratory discussed herein were supported by NIH grants CA65525 and CA80176.

\section{References}

Andreassen, A., Mollersen, L., Vikse, R., Steffensen, I. L., Mikalsen, A., Paulsen, J. E. and Alexander, J. (2002) One dose of 2-amino-1-methyl-6-phenylimidazo[4,5- $b$ ]pyridine (PhIP) or 2-amino-3-methylimidazo[4,5-f]quinoline (IQ) induces tumours in Min/+ mice by truncation mutations or $\mathrm{LOH}$ in the $A p c$ gene. Mutat. Res. 517, 157-166.

Andreassen, A., Vikse, R., Steffensen, I. L., Paulsen, J. E. and Alexander, J. (2001) Intestinal tumours induced by the food carcinogen 2-amino-1-methyl-6-phenylimidazo[4,5-b]pyridine in multiple intestinal neoplasia mice have truncation mutations as well as loss of the wild-type $\mathrm{Apc}^{+}$allele. Mutagenesis 16, 309315.

Anzai, N., Taniyama, T., Nakandakari, N., Sugiyama, C., Negishi, T., Hayatsu, H and Negishi, K. (2001) Inhibition of DNA adduct formation and mutagenic action of 3-amino-1-methyl$5 \mathrm{H}$-pyrido[4,3-b]indole by chlorophyllin-chitosan in $r p s L$ transgenic mice. Jpn. J. Cancer Res. 92, 848-853.

Bol, S. A., Horlbeck, J., Markovic, J., de Boer, J. G., Turesky, R. J. and Constable, A. (2000) Mutational analysis of the liver, colon and kidney of Big Blue rats treated with 2-amino-3methylimidazo[4,5-f]quinoline. Carcinogenesis 21, 1-6.

Collett, G. P., Robson, C. N., Mathers, J. C. and Campbell, F. C. (2001) Curcumin modifies Apc(min) apoptosis resistance and inhibits 2-amino 1-methyl-6-phenylimidazo[4,5-b]pyridine $(\mathrm{PhIP})$ induced tumour formation in $\mathrm{Apc}(\mathrm{min})$ mice. Carcinogenesis 22, 821-825.

Dashwood, R. H. (2002) Modulation of heterocyclic amineinduced mutagenicity and carcinogenicity: an 'A-to-Z' guide to chemopreventive agents, promoters, and transgenic models. Mutat. Res. 511, 89-112.

Dass, S. B., Bucci, T. J., Heflich, R. H. and Casciano, D. A. (1999) Evaluation of the transgenic p53+/- mouse for detecting genotoxic liver carcinogens in a short-term bioassay. Cancer Lett. 143, 81-85.

Davis, C. D., Dacquel, E. J., Schut, H. A. J., Thorgeirsson, S. S and Snyderwine E G. (1996) In vivo mutagenicity and DNA adduct levels of heterocyclic amines in Muta mice and c-myc/ lacZ double transgenic mice. Mutat. Res. 356, 287-296.

Felton, J. S., Knize, M. G., Salmon, C. P., Malfatti, M. A. and Kulp, K. S. (2002) Human exposure to heterocyclic amine food mutagens/carcinogens: relevance to breast cancer. Environ. Mol. Mutagen. 39, 112-118.

Hein, D. W., Doll, M. A., Fretland, A. J., Leff, M. A., Webb, S. J., Xiao, G. H., Devanaboyina, U. S., Nangju, N. A. and Feng, 
Y. (2000) Molecular genetics and epidemiology of the NAT1 and NAT2 acetylation polymorphisms. Cancer Epidemiol. Biomarkers \& Prev. 9, 29-42.

Huelsken, J. and Behrens, J. (2002) The Wnt signalling pathway. J. Cell Sci. 115, 3977-3978.

Itoh, T., Suzuki, T., Nishikawa, A., Furukawa, F., Takahashi, M., Xue, W., Sofuni, T. and Hayashi, M. (2000) In vivo genotoxicity of 2-amino-3,8-dimethylimidazo[4, 5-f]quinoxaline in lacI transgenic (Big Blue) mice. Mutat. Res. 468, 19-25.

Kakiuchi, H., Watanabe, M., Ushijima, T., Toyota, M., Imai, K., Weisburger, J. H., Sugimura, T. and Nagao, M. (1995) Specific 5'-GGGA-3' $\rightarrow$ 5'-GGA-3' mutation of the Apc gene in rat colon tumors induced by 2-amino-1-methyl-6phenylimidazo[4,5-b]pyridine. Proc. Natl. Acad. Sci. USA 92, 910-904.

Klein, J. C., Beems, R. B., Zwart, P. E., Hamzink, M., Zomer, G., van Steeg, H. and van Kreijl, C. F. (2001) Intestinal toxicity and carcinogenic potential of the food mutagen 2-amino-1methyl-6-phenylimidazo[4,5-b]pyridine (PhIP) in DNA repair deficient $\mathrm{XPA}^{-1-}$ mice. Carcinogenesis 22, 619-626.

Lynch, A. M., Gooderham, N. J., Davies, D. S. and Boobis, A. R. (1998) Genetic analysis of PhIP intestinal mutations in MutaMouse. Mutagenesis 13, 601-605.

Masumura, K., Matsui, K., Yamada, M., Horiguchi, M., Ishida, K., Watanabe, M., Ueda, O., Suzuki, H., Kanke, Y., Tindall, K. R., Wakabayashi, K., Sofuni, T. and Nohmi, T. (1999) Mutagenicity of 2-amino-1-methyl-6-phenylimidazo[4,5$b$ ]pyridine ( $\mathrm{PhIP})$ in the new gpt delta transgenic mouse. Cancer Lett. 143, 241-244.

Masumura, K., Matsui, K., Yamada, M., Horiguchi, M., Ishida, K., Watanabe, M., Wakabayashi, K. and Nohmi, T. (2000) Characterization of mutations induced by 2-amino-1-methyl-6phenylimidazo[4,5- $b$ ]pyridine in the colon of gpt delta transgenic mouse: novel G:C deletions beside runs of identical bases. Carcinogenesis 21, 2049-2056.

Morimura, K., Salim, E. I., Yamamoto, S., Wanibuchi, H. and Fukushima, S. (1999) Dose-dependent induction of aberrant crypt foci in the colons but no neoplastic lesions in the livers of heterozygous p53-deficient mice treated with low dose 2amino-3-methylimidazo[4,5-f]quinoline. Cancer Lett. 138, 8185.

Nagao, M. and Sugimura, T., eds. (2000) Food Borne Carcinogens: Heterocyclic Amines. Wiley \& Sons, Chichester, England.

Nagao, M., Ushijima, T., Watanabe, N., Okochi, E., Ochiai, M., Nakagama, H. and Sugimura, T. (2002) Studies on mammary carcinogenesis induced by a heterocyclic amine, 2-amino-1methyl-6-phenylimidazo[4,5- $b$ ]pyridine, in mice and rats. Environ. Mol. Mutag. 39, 158-164.

Okochi, E., Watanabe, N., Shimada, Y., Takahashi, S., Wakazono, K., Shirai, T., Sugimura, T., Nagao, M. and Ushijima, T. (1999) Preferential induction of guanine deletion at 5'-GGGA3 ' in rat mammary glands by 2-amino-1-methyl-6phenylimidazo[4,5-b]pyridine. Carcinogenesis 20, 1933-1938.

Orner, G. A., Dashwood, W.-M., Blum, C. A., Díaz, G. D., Li, Q., Al-Fageeh, M., Tebbutt, N., Heath, J. K., Ernst, M. and Dashwood, R. H. (2002a) Response of $A p c^{\text {min }}$ and $A 33^{\Delta \mathrm{N} \beta \text {-cat }}$ mutant mice to treatment with tea, sulindac, and 2-amino-1methyl-6-phenylimidazo[4,5-b]pyridine (PhIP). Mutat. Res. 506, 121-127.
Orner, G. A., Dashwood, W.-M., Blum, C. A., Díaz, G. D., Li, Q. and Dashwood, R. H. (2002b) Suppression of tumorigenesis in the $A p c^{\text {min }}$ mouse: down-regulation of $\beta$-catenin signaling by a combination of tea plus sulindac. Carcinogenesis, in press.

Orner, G. A., Dashwood, W.-M., Li, Q., Al-Fageeh, M., Tebbutt, N., Heath, J. K., Ernst, M. and Dashwood, R. H. (2002c) Cellular effects of tea antioxidants in vitro and in mouse models of colorectal cancer: modulation of Wnt signaling. Free Radic. Res. 36, 16-20.

Oshima, M., Oshima, H., Tsutsumi, M., Nishimura, S., Sugimura, T., Nagao, M. and Taketo, M. M. (1996) Effects of 2-amino-1methyl-6-phenylimidazo[4,5- $b$ ]pyridine on intestinal polyp development in $A p c^{\Delta 716}$ knockout mice. Mol. Carcinog. 15, 1117.

Park, C. B., Kim, D. J., Uehara, N., Takasuka, N., Hiroyasu, B. T. and Tsuda, H. (1999) Heterozygous p53-deficient mice are not susceptible to 2-amino-3,8-dimethylimidazo[4,5-f]quinoxaline (MeIQx) carcinogenicity. Cancer Lett. 139, 177-182.

Paulsen, J. E., Steffensen, I. L., Andreassen, A., Vikse, R. and Alexander, J. (1999) Neonatal exposure to the food mutagen 2amino-1-methyl-6-phenylimidazo[4,5-b]pyridine via breast milk or directly induces intestinal tumors in multiple intestinal neoplasia mice. Carcinogenesis 20, 1277-1282.

Polakis, P. (2000) Wnt signaling and cancer. Genes Dev. 14, 18371851.

Ryu, D. Y., Pratt, V. S., Davis, C. D., Schut, H. A. and Snyderwine, E. G. (1999) In vivo mutagenicity and hepatocarcinogenicity of 2-amino-3,8-dimethylimidazo[4,5- $f$ ] quinoxaline (MeIQx) in bitransgenic c-myc/lambda lacZ mice. Cancer Res. 59, 2587-2592.

Schoeffner, D. J. and Thorgeirsson, U. P. (2000) Susceptibility of nonhuman primates to carcinogens of human relevance. In Vivo 14, 149-156.

Schwab, C. E., Huber, W. W., Parzefall, W., Hietsch, G., Kassie, F., Schulte-Hermann, R. and Knasmuller, S. (2000) Search for compounds that inhibit the genotoxic and carcinogenic effects of heterocyclic aromatic amines. Crit. Rev. Toxicol. 30, 1-69.

Skog, K. (2002) Problems associated with the determination of heterocyclic amines in cooked foods and human exposure. Food Chem. Toxicol. 40, 1197-1203.

Skog, K. and Solyakov, A. (2002) Heterocyclic amines in poultry products: a literature review. Food Chem. Toxicol. 40, 12131221.

Sorensen, I. K., Kristiansen, E., Mortensen, A., van Kranen, H., van Kreijl, C., Fodde, R. and Thorgeirsson, S. S. (1997) Shortterm carcinogenicity testing of a potent murine intestinal mutagen, 2-amino-1-methyl-6-phenylimidazo(4,5-b)pyridine $(\mathrm{PhIP})$, in $A p c^{1638 \mathrm{~N}}$ transgenic mice. Carcinogenesis 18, 777781.

Steffensen, I. L., Paulsen, J. E. and Alexander, J. (2002) The food mutagen 2-amino-9H-pyrido[2,3-b]indole (AalphaC) but not its methylated form (MeAalphaC) increases intestinal tumorigenesis in neonatally exposed multiple intestinal neoplasia mice. Carcinogenesis 23, 1373-1378.

Stuart, G. R., de Boer, J. G., Haesevoets, R., Holcroft, J., Kangas, J., Sojonky, K., Thorleifson, E., Thornton, A., Walsh, D. F., Yang, H. and Glickman, B. W. (2001) Mutations induced by 2amino-1-methyl-6-phenylimidazo[4,5-b]pyridine (PhIP) in cecum and proximal and distal colon of lacI transgenic rats. Mutagenesis 16, 431-437. 
Stuart, G. R., Thorleifson, E., Okochi, E., de Boer, J. G., Ushijima, T., Nagao, M. and Glickman, B. W. (2000) Interpretation of mutational spectra from different genes: analyses of PhIP-induced mutational specificity in the lacI and cII transgenes from colon of Big Blue rats. Mutat. Res. 452, 101-121.

Sugimura, T., Kawachi, T., Nagao, M., Yahagi, T., Seino, Y., Okamoto, T., Shudo, K., Kosuge, T., Tsuji, K., Wakabayashi, K., Iitaka, Y. and Itai, A. (1977) Mutagenic principle(s) in tryptophan and phenylalanine pyrolysis products. Proc. Jpn. Acad. 53, 58-61.

Tebbutt, N. C., Johnstone, C. N., Demmler, K., Grail, D., Heath, J. K. and Ernst, M. (2000) Generation of mice expressing conditional oncogenes in intestinal epithelial cells. Proc. Am. Assoc. Cancer Res. 41, 848.

Turesky, R. J. (2002) Heterocyclic aromatic amine metabolism, DNA adduct formation, mutagenesis, and carcinogenesis. Drug
Metab. Rev. 34, 625-650.

Widmark, E. M. P. (1939) Presence of cancer-producing substances in roasted food. Nature 143, 984.

Yang, H., Stuart, G. R., Glickman, B. W. and de Boer, J. G. (2001) Modulation of 2-amino-1-methyl-6-phenylimidazo[4,5$b$ pyridine-induced mutation in the cecum and colon of big blue rats by conjugated linoleic acid and 1,2-dithiole-3-thione. Nutr. Cancer 39, 259-266.

Yang, H., Glickman, B. W. and de Boer, J. G. (2002) Sex-specific induction of mutations by PhIP in the kidney of male and female rats and its modulation by conjugated linoleic acid. Environ. Mol. Mutag. 40, 116-121.

Zhang, S., Lloyd, R., Bowden, G., Glickman, B. W. and de Boer, J. G. (2001) Msh2 DNA mismatch repair gene deficiency and the food-borne mutagen 2-amino-1-methy-6-phenylimidazo[4,5b]pyridine (PhIP) synergistically affect mutagenesis in mouse colon. Oncogene 20, 6066-6072. 